\title{
HIV Nef enhances the expression of oncogenic c-MYC and activation-induced cytidine deaminase in Burkitt lymphoma cells, promoting genomic instability
}

Nontlantla Mdletshe, Andrew Nel, Karen Shires and Shaheen Mowla ${ }^{*}$

\begin{abstract}
Background: Non-Hodgkin lymphoma is of high prevalence among HIV-infected people. In particular, the incidence of HIV-associated Burkitt lymphoma (BL) remains high despite the advent of Highly Active Anti-Retroviral Therapy. Recent evidence shows that serum-soluble HIV proteins can enhance oncogenesis, particularly in lymphoid tissues. This study sought to define the role of HIV protein Negative regulatory factor (Nef) in BL development by assessing its effect on key lymphoma driver genes.

Methods: A recombinant Nef protein was used to assess changes in expressions of activation-induced cytidine deaminase (AICDA/AID) and c-MYC in B lymphocytes exposed extracellularly to the protein. Additionally, changes in the promoter activities of these genes were measured using a Nef-expressing cellular model and reporter assays. Confocal microscopy was used to observe c-MYC and AID expression and localization, and genomic integrity via the recruitment of phosphorylated $\gamma-\mathrm{H} 2 \mathrm{AX}$, in Nef-exposed cells.

Results: mRNA transcription of c-MYC and AICDA were significantly enhanced in lymphoma cells, up to 2-fold for cMYC and up to 4-fold for AICDA, when exposed to varying concentrations of Nef $(0-1000 \mathrm{ng} / \mathrm{ml})$ and for different periods of time $(3,6$ and $12 \mathrm{~h})$. The protein expressions of AID and c-MYC followed a similar pattern and these effects were specific to BL but not lymphoblastoid cells. While the promoter activity of c-MYC was enhanced in the presence of Nef in a dose-dependent manner, the same was not observed for AICDA. Both AID and c-MYC accumulated within the cytoplasmic and nuclear spaces of Nef-exposed lymphoma cells, with a concomitant increase in DNA double strand breaks within the genome.

Conclusions: Exposure to HIV Nef leads to significant increases in AID and c-MYC, leading to genomic instability, potentially enhancing the oncogenic potential of Burkitt lymphoma. Our findings align with that of others to show that HIV proteins can directly contribute to the development and pathogenesis of HIV-associated lymphoma and accounts for the elevated incidence of BL observed in the HIV-infected population.
\end{abstract}

Keywords: HIV, Nef, Burkitt lymphoma, c-MYC, AID, Genome integrity

\footnotetext{
* Correspondence: shaheen.mowla@uct.ac.za

Division of Haematology, Department of Pathology, Faculty of Health Sciences, University of Cape Town, Observatory, Cape Town 7925, South Africa
}

C C The Author(s). 2020 Open Access This article is licensed under a Creative Commons Attribution 4.0 International License, which permits use, sharing, adaptation, distribution and reproduction in any medium or format, as long as you give appropriate credit to the original author(s) and the source, provide a link to the Creative Commons licence, and indicate if changes were made. The images or other third party material in this article are included in the article's Creative Commons licence, unless indicated otherwise in a credit line to the material. If material is not included in the article's Creative Commons licence and your intended use is not permitted by statutory regulation or exceeds the permitted use, you will need to obtain permission directly from the copyright holder. To view a copy of this licence, visit http://creativecommons.org/licenses/by/4.0/ The Creative Commons Public Domain Dedication waiver (http://creativecommons.org/publicdomain/zero/1.0/) applies to the data made available in this article, unless otherwise stated in a credit line to the data. 


\section{Background}

Burkitt Lymphoma (BL) is a highly aggressive NonHodgkin lymphoma (NHL) of B cell origin and the first haematological malignancy to be associated with HIV infection [1]. Its pathogenesis is strongly linked to the overexpression of c-MYC, an oncogenic transcription factor and an important regulator of apoptosis, cell growth and cellular metabolism [2]. The overexpression of c-MYC is described in a majority of cancer types and shown to contribute to the cause of at least $40 \%$ of tumours [3]. In $\mathrm{BL}, c-M Y C / I G H$ translocation events are described as a hallmark of the disease, with $t(8 ; 14)(q 24$; q32) being the most frequent (70-80\% of cases) [4]. Importantly, the $c-M Y C$ translocation event has been shown to be dependent on expression of the B-cell specific protein Activation-Induced cytidine Deaminase (AID), an essential enzyme in antibody diversification in B cell immune responses $[5,6]$. Both somatic hypermutation and class switching require AID which converts deoxycytidines to deoxyuracils in single-stranded DNA. Therefore the expression of this enzyme warrants tight regulation to prevent aberrant expression. The deregulation of AID activity has been observed especially in cancers of the B cell lineage, and interestingly a study in Diffuse Large B Cell Lymphoma patients who underwent $\mathrm{CHOP}$ based chemotherapy (cyclophosphamide, doxorubicin, vincristine, and prednisone) found that elevated AID expression can be used as a marker of unfavourable outcome $[7,8]$.

Compared to the HIV negative population, people living with HIV have a reported 70-200 times greater risk of developing an HIV-related lymphoma, and the risk remains high even after the start of antiretroviral therapy $[9,10]$. A 2017 study of a national hospital-based cancer registry dataset in the United States found that HIV/AIDS continues to be independently associated with increased risk of death among patients with lymphoma [11]. Surprisingly, a few reports have found a significant proportion of HIV positive patients develop BL even when not severely immunosuppressed, having CD4 counts $>200$ cells $/ \mathrm{mm}^{3}$ and suggest that the pathobiology of HIV-BL is unique despite similarities at the macroscopic and microscopic levels across the various BL subtypes namely sporadic, endemic and HIV-related [12, 13].

In recent years, new evidence has emerged supporting a direct role for HIV and its viral components in driving the oncogenic process. For instance, the HIV-1 matrix protein $\mathrm{p} 17$, which has long term persistence in the tissues of HIV positive patients on HAART, was reported to induce angiogenesis by binding to the chemokine receptors CXCR1 and CXCR2 [14]. Furthermore, recent reports show that HIV-1 transactivator of transcription (Tat) protein could contribute to the remodelling of the B-cell nucleus, inducing oxidative DNA damage and increasing the probability of c- MYC / IGH translocations [15]. While HIV does not infect B cells, studies suggest that serum-soluble HIV proteins could function as biologically active extracellular proteins released by infected cells and/or be transported inside uninfected $B$ cells where they disrupt normal cellular function and act as contributors to oncogenesis [16, 17]. The HIV Negative regulatory factor (Nef), a multifunctional 27-kDa protein is one of the first HIV proteins to be produced in infected cells and the most immunogenic of the accessory proteins [18]. Nef interacts with the host cells' signal transduction proteins providing long term survival of the infected $\mathrm{T}$ cells. It can also promote apoptosis of uninfected $\mathrm{T}$ cells and the endocytosis and degradation of cell surface receptors such as CD4 and MHC proteins. This impairs cytotoxic $\mathrm{T}$ cell function which helps the virus evade the host's immune response. While the Nef genes of HIV are dispensable in vitro, they are essential for efficient viral spread and disease progression in vivo. Nef is detected in the serum of HIV infected patients, even those who are virally suppressed $[19,20]$. In vitro, Nef has been shown to lead to overexpression of the B lymphocyte stimulator BLyS by monocyte-derived denditric cells, and has also been shown to travel from infected macrophages into B cells along actin-propelled conduits [21, 22].

In a recent study Nef was found to actively drive lung cancer in HIV infected patients in whom lung cancer develop on average a decade earlier than uninfected patients [23, 24]. In the presence of Nef, lung cells were found to have increased proliferative and invasive capabilities, and enhancement in expression of vascular endothelial growth factor $\mathrm{A}$ (VEGF-A), a key facilitator of angiogenesis. In Kaposi sarcoma Nef has been shown to synergize with the human herpesvirus 8 protein $\mathrm{K} 1$ to promote cellular proliferation and angiogenesis through the phosphatase and tensin homolog / protein kinase B / mammalian target of rapamycin (PTEN/ $\mathrm{AKT} / \mathrm{mTOR}$ ) pathway mediated by miRNA-718 [25]. In B cells, the mechanisms by which Nef may contribute to lymphoma, either from external binding or via internalisation remains to be elucidated. One potential mechanism by which Nef could enhance B-cell lymphoma development is via enhancing the expression of proto-oncogenes. The aim of this study was to determine whether the HIV-1 protein Nef can affect the expression of AID and c-MYC, two important role players in Burkitt lymphoma development, and the impact that this may have on the B cell genome.

\section{Methods}

\section{Cell lines, cell treatments and plasmid constructs}

The Ramos cell line (ATCC ${ }^{\oplus}$ CRL-1596 ${ }^{\mathrm{Tm}}$ ) was obtained from the American Type Culture Collection (ATCC, USA) and cultured in Roswell Park Memorial Institute (RPMI) medium containing 10\% fetal calf serum (FCS) (Biochrom, Germany) and $1 \%$ penicillin-streptomycin 
(PS) (Sigma-Aldrich, USA). The EBV-immortalized B lymphoblastoid cell line (L1439A), was produced at the University of Cape Town (Division of Chemical Pathology) using an adapted protocol and cultured in Dulbecco's Modified Eagle Media (DMEM) medium containing $20 \%$ FCS with $1 \%$ PS [26]. The HT1080 cells were cultured in DMEM containing 10\% FCS and 1\% PS. All media were from Sigma-Aldrich (USA). All cultures were maintained at $37^{\circ} \mathrm{C}$ in a humidified $5 \% \mathrm{CO}_{2}$ incubator.

The pcDNA-Nef construct was donated by Professor Mitra (National Centre for Cell Science, India) [27] and the pET-14b-NEF SF2 construct was kindly donated by Professor Smithgall (University of Pittsburgh, USA) [28]. The pGL3-cMyc plasmid was a kind gift from Professor Dai (University of California USA) [29]. pRL-TK was a kind gift from Professor Prince (University of Cape Town). The pGL3-hAID construct was produced by cloning of a $\sim 2000$ bp 5 '-UTR sequence upstream of the Transcription start site (TSS) of the AICDA gene into the pGL3Basic backbone (Promega, USA). For cell treatments, cells were plated and exposed to Nef (or control) by adding purified His-tagged protein directly to cell cultures at indicated concentrations and incubated for 3, 6 and $12 \mathrm{~h}$.

\section{Production of recombinant His-tagged HIV Nef}

The E.coli strain BL21 pLysS was transformed with either pET-14b-NEF SF2 or pET21+ (control) and grown until mid-log phase when synthesis of the His-tagged recombinant HIV protein was induced by isopropyl $\beta$-D1-thiogalactopyranoside (IPTG; $1 \mathrm{mM}$ final conc.) for $4 \mathrm{~h}$ at $25^{\circ} \mathrm{C}$. His-tagged protein was isolated using the HisSpin protein miniprep system (Zymo Research, USA). Lysate from cells transformed with the pET21+ empty vector was used as control. Bacterial endotoxins were removed using the High Capacity Endotoxin Removal Resin (Pierce, USA). Purified recombinant protein was quantified using a BCA Assay (Thermo Scientific ${ }^{\mathrm{Tm}}$, USA) and specificity and purity were assessed using SDSPAGE and western blotting.

\section{SDS-PAGE and Western blot analyses}

Total protein extracts were prepared using RIPA lysis buffer: $150 \mathrm{mM} \mathrm{NaCl}, 1 \%$ Triton X-100, $0.1 \%$ SDS, $10 \mathrm{mM}$ Tris- $\mathrm{HCl}$ (pH 7.5), 1\% deoxycholate, supplemented with protease inhibitors (Roche, Switzerland). Proteins were resolved on $8-12 \%$ SDS-polyacrylamide gels, transferred to Hybond ECL membranes (Amersham Biosciences, USA), probed with appropriate primary antibodies, detected using peroxidase-conjugated secondary antibodies and visualized by ECL (Pierce, USA). Antibodies: HIV-1 Nef antiserum (2949 - NIH AIDS Research and Reference Reagent Program; 1:1000); anti-c-MYC (SC-764, Santa Cruz Biotechnology, USA; 1:1000); anti-AID (392,500,
Thermofisher Scientific, USA; 1:1000); anti-p38 (M0800, Sigma USA; 1:5000).

\section{Quantitative real time PCR}

Total RNA was extracted using the Highpure RNA isolation kit (Roche, Switzerland). Reverse transcription $(1 \mu \mathrm{g})$ was performed using the iScript ${ }^{\mathrm{Tm}}$ cDNA Synthesis Kit (Bio-Rad, USA). Real-time PCR was performed on a LightCycler 480 (Roche, Germany) using KAPA SYBR ${ }^{\circ}$ FAST qPCR Kit (Kapa Biosystems, South Africa). Relative mRNA expression levels were normalized to GAPDH for each reaction with PCR efficiency correction calculated using the formula Ratio $=(\text { Etarget })^{\mathrm{CPtarget}(\text { control }- \text { sample })} /$

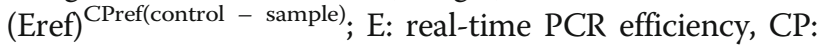
crossing-point. Primers used to amplify the human $A I C D A, c-M Y C$ and GAPDH genes were manufactured by IDT (Qiagen, Germany). Primers: AID-forward 5`-CCAA ACCATCTCTCCAAAGC-3`, AID-reverse 5` - CATCCC CACCCATAACAATC-3`; c-MYC-forward 5`- CTGAGA CAGATCAGCAACAACC-3`, c-MYC-reverse 5`- TTGT GTGTTCGCCTCTTGAC-3`; GAPDH-forward 5' - CAGGAGGCATTGCTGATGAT-3'; GAPDH-reverse 5' GAAGGCTGGGGCTCATTT-3'.

\section{Transfections and luciferase assays}

Transient transfections were performed using XtremeGene HP (Roche, Switzerland). Cells were plated to achieve $70-80 \%$ confluency at the time of transfection. HT1080 cells were transfected with $500 \mathrm{ng}$ per well of luciferase reporter constructs for human AID (pGL3-hAID) or c-MYC (pGL3-cMYC) and 0-500 ng of pcDNA-Nef or empty vector per well. The vector pRL-TK was used as an internal control for transfection efficiency. Cells were cultured for $30 \mathrm{~h}$ and extracts were assayed for firefly and renilla luciferase activity using the dual luciferase assay system (Promega, USA). Luciferase activities were measured using the Luminoskan Ascent luminometer (Thermo Labsystems, Franklin, MA, USA). Firefly luciferase values were normalised to the renilla luciferase activity and expressed relative to empty vector control.

\section{Immunocytochemistry and confocal microscopy}

Cells were plated and treated as indicated and thereafter transferred to microfuge tubes, pelleted, washed $2 \mathrm{x}$ in PBS and fixed using 4\% PFA. Cells were washed again in PBS, permeabilized with $0.3 \%$ Triton $\mathrm{x}-100$ in PBS, and then washed in PBS containing $0.1 \%$ Tween-20. Cells were blocked for $1 \mathrm{~h}$ in PBS $+5 \%$ swine serum and incubated overnight at room temperature in primary antibody (anti-c-MYC/anti-AID/anti-phospho-Histone H2A; Cell signalling technology, USA; 1:100 dilution) diluted in blocking buffer. After $2 \mathrm{x}$ washes in PBS $+0.1 \%$ Tween-20, cells were incubated in fluorescently labelled (Cy3) secondary antibody for $1 \mathrm{~h}$ at room temperature. 
Cells were thereafter spun and the pellet washed $2 \mathrm{x}$ in PBS and then stained with $1 \mu \mathrm{g} / \mathrm{ml}$ DAPI in PBS for 10 min, mounted on a slide with Mowial mounting medium containing anti-fade (Sigma, USA) and examined the next day using confocal microscopy.

\section{Statistical analysis}

All cell treatments, qPCR and luciferase reporter assays were performed at least in triplicate. Statistical analysis was done using the GraphPad Prism software and significance between groups was determined using the Mann-Whitney $\mathrm{U}$ test (two-tailed) and $p$ values $<0.05$ were considered significant.

\section{Results}

\section{Extracellular exposure to recombinant HIV Nef leads to} upregulation of c-MYC and AID in lymphoma cells

To mimic an in vivo scenario where B cells are exposed to soluble HIV proteins found in the serum of HIV infected individuals, B lymphocytes were extracellularly exposed to varying concentrations of recombinant $\mathrm{Nef}$ protein for various lengths of time. The amount of Nef present in the serum of a patient is dependent on several factors including viral load and studies have reported up to $1000 \mathrm{ng} / \mathrm{ml}$ of Nef being detected in the serum of HIV positive individuals, and in vitro studies have used up to $1000 \mathrm{ng} / \mathrm{ml}$ recombinant Nef protein in exogenous assays [30, 31]. In our study, cells were exposed to 0 , 200, 500 and $1000 \mathrm{ng} / \mathrm{ml}$ of recombinant Nef, over a period of 3, 6 and $12 \mathrm{~h}$. As can be seen in Fig. 1a, exposure of lymphoblastoid cells (LCLs) to Nef led to a marginal increase in the expression of $c-M Y C$ mRNA at the earliest time point of $3 \mathrm{~h}$, and thereafter, at $6 \mathrm{~h}$ and $12 \mathrm{~h}$, no major increases were recorded, and interestingly, it appeared that $c-M Y C$ mRNA levels decreased slightly below control levels. In the Burkitt lymphoma cell line Ramos, Nef exposure led to a higher increase in $c-M Y C$ transcription compared to LCLs at the $3 \mathrm{~h}$ time point, and was sustained at $6 \mathrm{~h}$ and $12 \mathrm{~h}$, especially at 200 and $500 \mathrm{ng} / \mathrm{ml}$ of recombinant Nef exposure. This difference in response between the LCLs and the Ramos cells is even more apparent for AICDA expression, with the shortest exposure of $3 \mathrm{~h}$ showing the largest differential response. Up to a 4.6-fold increase in AICDA mRNA was recorded for Ramos cells when exposed to $500 \mathrm{ng} /$ $\mathrm{ml} \mathrm{Nef}$ for $3 \mathrm{~h}$, compared to a marginal increase of 1.2 in the LCLs. At the 6 and $12 \mathrm{~h}$ time points, the response was less robust in the Ramos cells, albeit still slightly higher than in LCLs. Once again, lower concentrations of Nef (200 and $500 \mathrm{ng} / \mathrm{ml})$ lead to larger increases in AICDA in the Ramos cells, compared to the higher concentration of $1000 \mathrm{ng} / \mathrm{ml}$.

To verify that changes in transcription led to changes in protein expression, western blotting was performed.
We chose to only assess changes in protein expression in the Ramos cells, and at the $3 \mathrm{~h}$ and $6 \mathrm{~h}$ time points only, since these were significantly more responsive to Nef exposure compared to the LCLs. We found that although the expression of both the c-MYC and AID protein were increased in Ramos cells exposed to Nef, these increases did not correlate exactly to the mRNA levels (Fig. 1b). At the $3 \mathrm{~h}$ time point, the c-MYC protein expressions were generally higher than the control $(0 \mathrm{ng}$ Nef) although a similar trend as $c-M Y C$ mRNA increase was not observed. At $6 \mathrm{~h}$ post-exposure, c-MYC protein expression was only enhanced when cells were exposed to the lower Nef concentration of $200 \mathrm{ng}$.

As seen for c-MYC, AID protein expression was enhanced at both the $3 \mathrm{~h}$ and $6 \mathrm{~h}$ time points. While a correlation with mRNA expression was not seen, it can be noted that at the earlier time point of $3 \mathrm{~h}$, AID protein expression was most pronounced when cells were exposed to the lower concentrations of Nef, while at the later time point of $6 \mathrm{~h}$, it would appear that AID protein levels at $200 \mathrm{ng} \mathrm{Nef}$ had gone back down to control levels, but were enhanced for the $500 \mathrm{ng}$ and $1000 \mathrm{ng}$ Nef exposures.

\section{Nef enhances the promoter activity of $c-M Y C$ but not that of $A I C D A$}

We sought to investigate whether the changes in $c-M Y C$ and AICDA expressions observed upon exposure to $\mathrm{Nef}$ were as a result of changes in the activity of the promoter of these genes in the presence of Nef. While B lymphocytes are not hosts for HIV, the viral proteins have been reported to become internalised within these cells [32]. Moreover, Nef has been shown to modulate the transcription of cellular genes and to cooperate with cellular proteins such as transcription factors to regulate genes [33, 34]. We used a luciferase reporter assay system to investigate whether Nef affects the promoter activities of both $c-M Y C$ and AICDA. The HT1080 cell line was transiently transfected with a constant amount of a luciferase reporter containing either the human $c$ $M Y C$ or AICDA promoter, as well as varying doses of a mammalian expression vector expressing Nef. We found that the activity of the $c-M Y C$ promoter significantly increased in a dose-dependent manner in the presence of increasing amounts of Nef protein, with a maximum increase of 2.5 fold observed when $500 \mathrm{ng}$ of the Nef expressing plasmid was used (Fig. $2 \mathrm{a}-$ top panel). On the other hand, the activity of the AICDA promotor was not significantly altered, even at high doses (Fig. $2 \mathrm{a}$ - bottom panel). Western blot analysis was used to demonstrate that increasing amounts of Nef-expressing plasmid correlated with increasing expression of the Nef protein within the cells (Fig. 2b). 


\section{a}
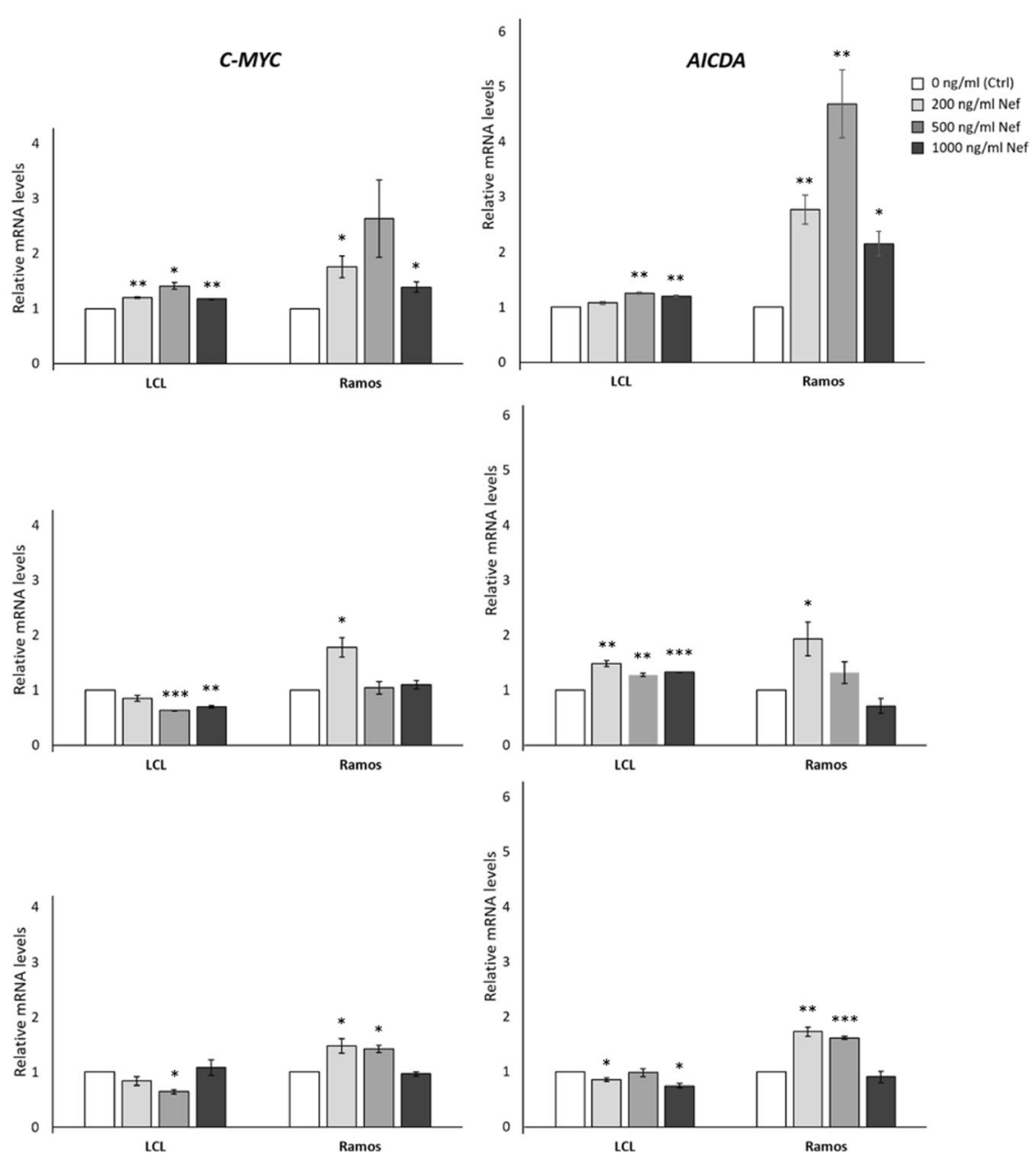

b
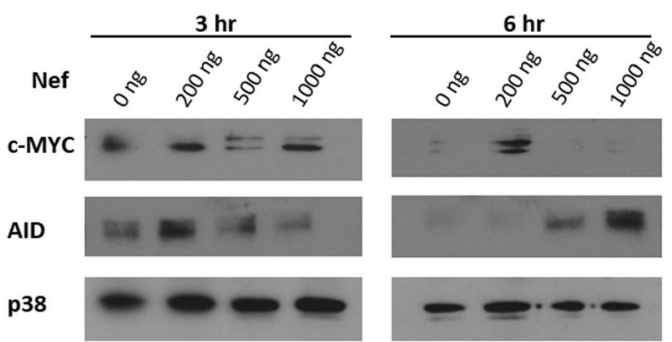

\section{Ramos}

Fig. 1 AID and c-MYC expressions are altered in B cells upon exposure to HIV Nef. a. Bar graphs showing relative mRNA expression of c-MYC (left panel) and AICDA (right panel) at $3 \mathrm{~h}, 6 \mathrm{~h}$ and $12 \mathrm{~h}$ exposure to HIV Nef, in lymphoblastoid cells (LCLs) and Burkitt lymphoma cells (Ramos). Cells were treated at the indicated concentrations of recombinant Nef, total RNA was isolated and qPCR was performed on reverse transcribed mRNA using primers specific to $c-M Y C$ or AICDA. The levels were normalised to the internal control GAPDH and plotted relative to mock (0 ng/ml) treated cells. ${ }^{* * *} p \leq 0.001 ;{ }^{* *} p \leq 0.01 ;{ }^{*} p \leq 0.05$. All experiments were performed in triplicate. Bars indicate standard deviation. b. Ramos cells were treated at the indicated concentrations of recombinant Nef, total protein was isolated, separated on 12\% SDS-PAGE and analysed by western blotting with antibodies against c-MYC and AID. p38 was detected as a loading control. All experiments were performed in triplicate 
a

Nef on $c-M Y C$ promoter activity

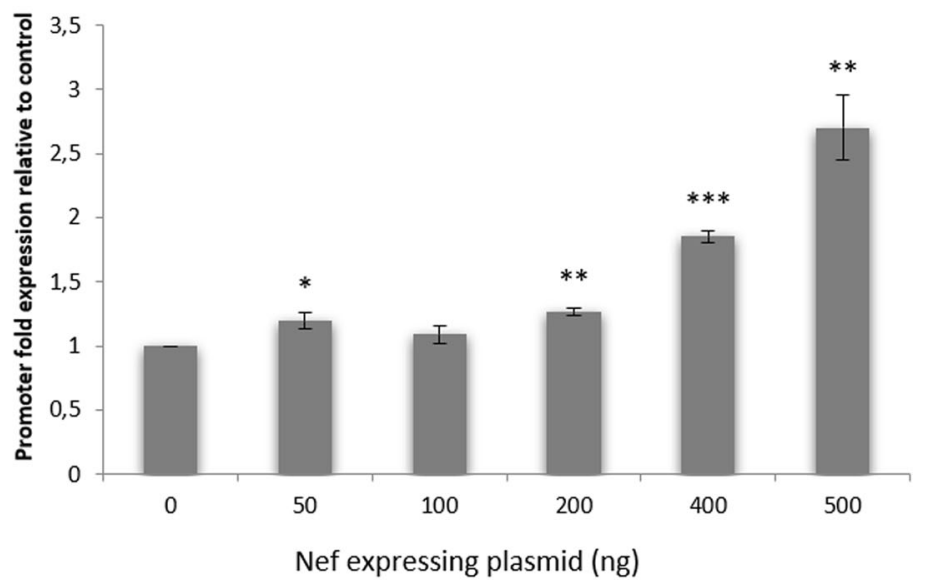

Nef on AICDA promoter activity

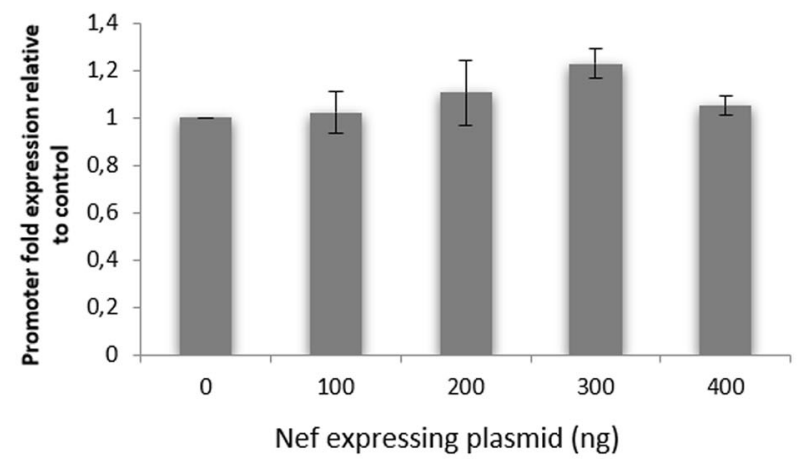

b

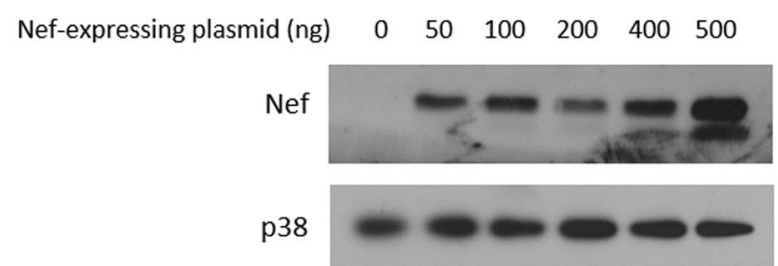

Fig. 2 HIV Nef activates the human C-MYC promoter, but not the AICDA promoter. a. Bar graphs showing promoter activities of C-MYC (top panel) and AICDA (bottom panel) when exposed to Nef, relative to control (empty vector). In both cases, the promoter-luciferase reporter construct (500 ng per well in $35 \mathrm{~mm}$ dish) was co-transfected into HT1080 cells with the internal control pRL-TK $(50 \mathrm{ng})$ in the presence of increasing concentrations of the Nef expressing vector pcDNA-Nef (0-500 ng) or empty vector (pcDNA3.1). Luciferase activity was measured $30 \mathrm{~h}$ posttransfection and normalized to renilla luciferase activity. Activation fold values were calculated by setting promoter activity exposed to pcDNA3.1 empty $(500 \mathrm{ng})$ to 1 . Mean values $( \pm)$ were calculated from three independent experiments. Bars indicate standard deviation. ${ }^{* * *} p \leq 0.001 ;{ }^{* *} p \leq$ $0.01 ;{ }^{*} p \leq 0.05$. All experiments were performed in triplicate. $\mathbf{b}$. To demonstrate that increasing amounts of Nef expressing plasmid leads to increasing expression of Nef protein, western blot analysis of whole proteins lysates from luciferase assays performed in HT1080 cells above was performed. Proteins were separated on 15\% SDS-PAGE, transferred onto nitrocellulose membranes and analysed using an antibody specific to Nef. p38 was detected as a loading control to demonstrate equal loading of protein lysates

Nef-driven AID over-expression leads to accumulation of c-MYC and increased genomic instability in lymphoma cells

The translocation and overexpression of oncogenic cMYC in B lymphocytes is intimately linked to the overexpression of AID, a protein which is known to induce double strand breaks in DNA [5, 35]. To further explore the downstream physiological consequences of Nef exposure, the Ramos BL cells were exposed to Nef and immunocytochemistry was performed followed by 
confocal fluorescence microscopy to study c-MYC and AID expression and localization, as well as genomic integrity using a specific marker for double strand breaks. As can be seen in Fig. 3, a clear increase in both c-MYC and AID can be seen in the BL cells exposed to the purified recombinant Nef protein, compared to the control cells. Within the Nef exposed cells, AID and c-MYC accumulated both within the cytoplasm and the nucleus. We investigated the integrity of the genome by assessing the presence of DSBs within the cells. H2AX phosphorylation is an early event in the DNA damage response (DDR) to different genotoxic stresses that induce DSBs and gets recruited to sites of DSBs within the genome [36]. Lymphoma cells exposed to HIV Nef harboured a significantly higher number of DSB sites within the DNA as observed by the increased detection of $\gamma$-H2AX-associated foci within these cells.

\section{Discussion}

HIV as an oncogenic virus and a driver of lymphoma is an emerging concept which is rapidly gaining credibility as more reports emerge supporting this. Numerous studies, including ours, do not only implicate Nef but also other soluble HIV proteins including Tat and p17 [14, 15, 24, 25]. In the latter cases, research has advanced to show that these viral proteins have the ability to exploit cellular components and pathways in complex ways to advance oncogenic events.

The ability of Nef to alter the expression of two important genes in the development of Burkitt lymphoma, namely $A I C D A$ and $c-M Y C$, was the focus of this study. We demonstrated an increase in the expression of these two markers at both the mRNA and protein levels in BL cells when exposed to HIV Nef. Previous studies have

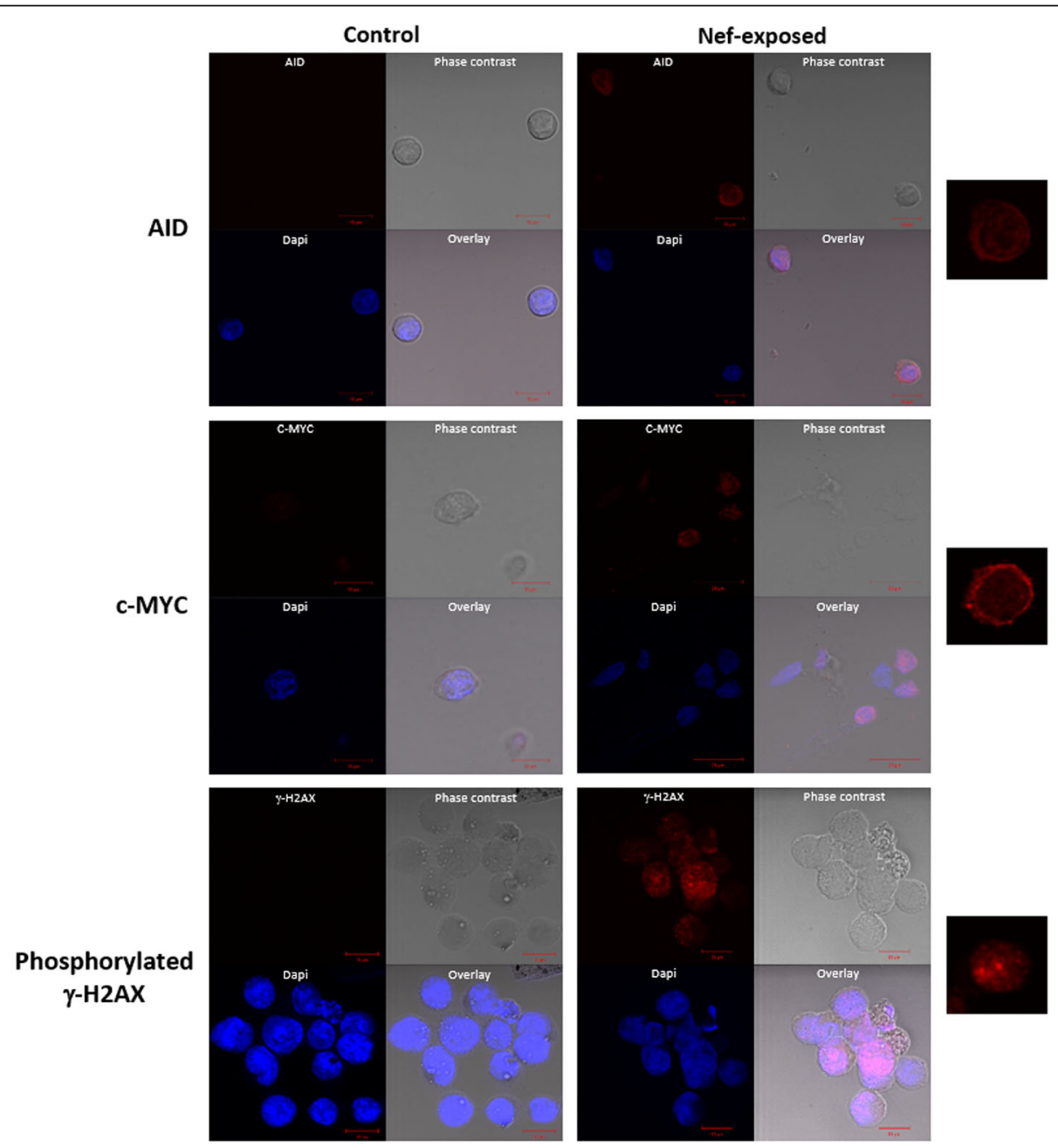

Fig. 3 Exposure to Nef leads to accumulation of c-MYC and AID in the cytoplasm and nuclei of lymphoma cells, enhancing genomic instability. Ramos cells were exposed to $500 \mathrm{ng} / \mathrm{ml}$ of HIV Nef for $3 \mathrm{~h}$. Thereafter cells were fixed and permeabilized. The presence of c-MYC, AID and $y-H 2 A X$ were detected with specific primary antibodies and fluorescently tagged (Cy3 - red) secondary antibodies. DNA was stained with Dapi (blue). Cells were mounted on slides and images were captured using confocal microscopy. Left hand panels represent cells which were mock-treated (protein prepared using empty vector), and right hand panels represent cells exposed to recombinant HIV Nef. On the far right hand side of each panel is a zoomed image of one representative Ramos cell from that panel 


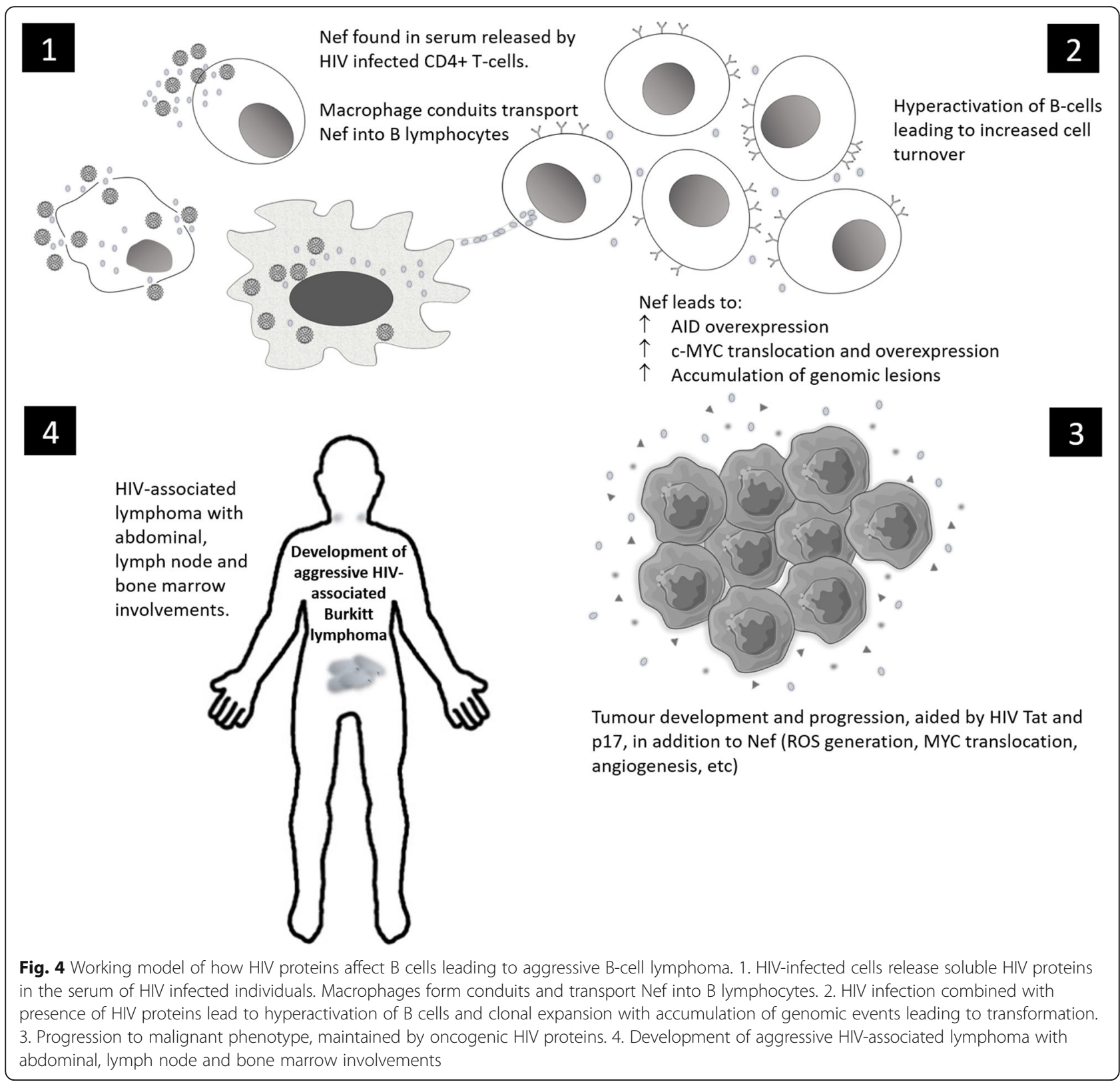

shown that AID is elevated in the PBMCs of HIVinfected individuals who later developed lymphoma and more recently, B-cells treated with recombinant Tat had an increase in the $A I C D A$ gene $[17,37]$. Our study shows yet another HIV protein, with demonstrated oncogenic potential, having a similar effect.

The oncogenicity of AID, via its mutagenic activity, is well described, not only in lymphoma but also in cancers of organs including the colon, lung and skin [38-41]. An enhancement in AID levels leads to cancer promoting features such as uncontrolled cellular proliferation and development of tumours in mice. Our findings confirm the well reported close relationship between AID and MYC expressions and we further demonstrate enhancement of MYC activity via its translocation into the nucleus where it can perform its primary function as a transcription factor. Future studies should focus on Nefs ability to affect cellular features including proliferation, apoptosis and invasiveness in lymphoma cells, which has recently been reported in lung cancer cells [24]. Additionally, HIV Nef and Tat have both been demonstrated to contribute to oncogenesis through cooperation with cellular miRNAs as well as other oncogenic viruses, and this too is another important area of investigation in the pathogenesis of HIV-associated lymphoma.

The recruitment of phosphorylated $\gamma-\mathrm{H} 2 \mathrm{AX}$ at numerous DSB foci within the nucleus of Nef exposed cells show a more unstable genome in the presence of the viral protein. We attribute this phenomenon to aberrant 
AID accumulation since the latter triggers class switch recombination (CSR) in B cells by initiating DNA double strand breaks. Genomic instability facilitates the accumulation of genetic lesions required to maintain the cancer phenotype and our study is supported by that of Germini et al. who showed that HIV Tat can induce DNA damage in B-cells in vitro [42].

Compared to lymphoma cells, the non-malignant lymphoblastoid cells showed very mild increases in AICDA and $c-M Y C$ upon exposure to Nef. This could indicate that the response is dependent on cell membrane components and that malignant cells become more responsive to oncogenic stimuli through the transformation process. Indeed, studies have shown that there are variations in the cell membrane carbohydrates between cancer and normal cell membranes and these differences translate into differential pathways and cellular uptake abilities [43].

We show that Nef could enhance the promoter activity of $c-M Y C$ but not that of AICDA. It is likely that extracellular exposure to Nef could affect a greater repertoire of genes, perhaps through ligand binding and activation of signalling pathways. However, upon internalisation the activity of Nef could be more specific and targeted. This is consistent with what has been observed for HIV p17 which has been shown to interact with the chemokine receptors CXCR1 and CXCR2 of B-cells, but the protein can also become internalized by a process not yet characterized [14]. We are invested in further defining the association between Nef and $c-M Y C$ transcription. While Nef may be acting as a transcription factor by directly binding to and enhancing the promoter activity, several reports support a role for Nef in cooperating with cellular transcription factors to alter transcription, including AP-1 and NF-kB [30].

While more investigations are needed to further define the mechanism of Nef-driven lymphoma, it is clear that HIV infection provides an additional layer of complexity in cancer development and progression. The illustration in Fig. 4 summarises our findings as well as that of other studies involving HIV Tat and p17, and provides a working model of how HIV proteins could be contributing to the development of aggressive B-cell derived malignancies in HIV infected individuals.

\footnotetext{
Abbreviations

AICDA / AID: Activation-Induced cytidine Deaminase; ATCC: American Type Culture Collection; BCA: Bicinchoninic acid; BL: Burkitt Lymphoma; CHOP: Cyclophosphamide, doxorubicin, vincristine, and prednisone; CSR: Class switch recombination; CXCR1: C-X-C motif chemokine receptor 1 CXCR2: C-X-C motif chemokine receptor 2; DAPI: 4',6-diamidino-2phenylindole; DMEM: Dulbecco's Modified Eagle Media; DSB: Double Strand Break; EBV: Epstein Barr Virus; ECL: Enhanced Chemiluminescence; FCS: Fetal Calf Serum; GAPDH: Glyceraldehyde 3-phosphate dehydrogenase; HAAR T: Highly active antiretroviral therapy; HIV: Human Immunodeficiency Virus; IDT: Integrated DNA technologies; IGH: Immunoglobulin heavy chain; LCL: Lymphoblastoid cells; Nef: Negative regulatory Factor; NHL: Non-
}

Hodgkin lymphoma; PBS: Phosphate Buffered Saline; PCR: Polymerase Chain Reaction; PS: Penicillin-streptomycin; RPMI: Roswell Park Memorial Institute; SDS-PAGE: Sodium dodecyl sulfate polyacrylamide gel electrophoresis; VEGFA: Vascular endothelial growth factor A

\section{Acknowledgements}

We wish to thank the NIH AIDS Reagent Program, Division of AIDS, NIAID, $\mathrm{NIH}$ for the Anti-HIV-1 Nef Monoclonal (EH1) from Dr. James Hoxie; Professors Jonathan Blackburn and Sharon Prince at the University of Cape Town; and the UCT confocal microscopy Unit.

\section{Authors' contributions}

SM - Conceptualized the research, developed the methodology, performed experiments and data analysis, sourced the funding, curates the data, supervised the research, and wrote and edited the manuscript. AN - Assisted with the development of some methodology and assisted with the execution of some experiments. NM - Performed experiments and some data analysis. KS - Wrote an early draft of the manuscript. The author(s) read and approved the final manuscript.

\section{Funding}

This research was made possible through support from the South African National Research Foundation (Funding for research costs); South African Medical Research Council (Funding for student bursary); National Health Laboratory Services (Funding for research costs); and the University of Cape Town Faculty of Health Sciences Research grant (Funding for research costs).

\section{Availability of data and materials}

The datasets used and/or analysed during the current study are available from the corresponding author on reasonable request.

\section{Ethics approval and consent to participate}

Not Applicable.

\section{Consent for publication}

Not Applicable.

\section{Competing interests}

The authors declare that they have no competing interests.

Received: 11 June 2020 Accepted: 31 August 2020

Published online: 04 September 2020

\section{References}

1. Schulz TF, Boshoff CH, Weiss RA. HIV infection and Neoplasia. Lancet. 1996; 348:587-91.

2. Hoffman B, Liebermann DA. Apoptotic signaling by c-MYC. Oncogene. 2008; 27(50):6462-72.

3. Dang CV, Le A, Gao P. MYC-induced cancer cell energy metabolism and therapeutic opportunities. Clin Cancer Res. 2009;15(21):6479-83.

4. Jack A, Barrans S. Recent advances in the understanding of aggressive B-cell lymphomas. Curr Diagn Pathol. 2004;10(5):360-73.

5. Ramiro AR, Jankovic M, Eisenreich T, Difilippantonio S, Chen-Kiang S, Muramatsu $\mathrm{M}$, et al. AID is required for c-myc/lgH chromosome translocations in vivo. Cell. 2004;118(4):431-8.

6. Robbiani DF, Bothmer A, Callen E, Reina-San-Martin B, Dorsett $Y$, Difilippantonio $S$, et al. Activation induced Deaminase is required for the chromosomal breaks in $\mathrm{c}-\mathrm{myc}$ that lead to $\mathrm{c}-\mathrm{myc} / \mathrm{lgH}$ translocations. Cell. 2009;135(6):1028-38.

7. Kawamura K, Wada A, Wang J-Y, Li Q, Ishii A, Tsujimura H, et al. Expression of activation-induced cytidine deaminase is associated with a poor prognosis of diffuse large B cell lymphoma patients treated with CHOPbased chemotherapy. J Cancer Res Clin Oncol. 2015;142(1):27-36.

8. Rebhandl S, Huemer M, Greil R, Geisberger R. AID/APOBEC deaminases and cancer. Oncoscience. 2015:2(4):320-33.

9. Vishnu P, Aboulafia DM. AIDS-related non-Hodgkin's lymphoma in the era of highly active antiretroviral therapy. Adv Hematol. 2012;485943.

10. Palmieri C, Treibel T, Large O, Bower M. AIDS-related non-Hodgkin's lymphoma in the first decade of highly active antiretroviral therapy. QJM. 2006;99(12):811-26. 
11. Han X, Jemal A, Hulland E, Simard EP, Nastoupil L, Ward E, et al. HIV infection and survival of lymphoma patients in the era of highly active antiretroviral therapy. Cancer Epidemiol Biomakers Prev. 2017;26(3):303-11.

12. Spina M, Simonelli C, Talamini R, Tirelli U. Patients with HIV with Burkitt's lymphoma have a worse outcome than those with diffuse large-cell lymphoma also in the highly active antiretroviral therapy era. J Clin Oncol. 2005;23(31):8132-3.

13. Lim ST, Karim R, Nathwani BN, Tulpule A, Espina B, Levine AM. AIDS-related Burkitt's lymphoma versus diffuse large-cell lymphoma in the pre-highly active antiretroviral therapy (HAART) and HAART eras: significant differences in survival with standard chemotherapy. J Clin Oncol. 2005;23(19):4430-8.

14. Martorelli D, Muraro E, Mastorci K, Dal Col J, Fae DA, Furlan C, et al. A natural HIV p17 protein variant up-regulates the LMP-1 EBV oncoprotein and promotes the growth of EBV-infected B-lymphocytes: implications for EBVdriven lymphomagenesis in the HIV setting. Int J Cancer. 2015;137(6):1374-85.

15. El-Amine R, Germini D, Zakharova W, Tsfasman T, Sheval EV, Louzada RAN, et al. HIV-1 tat protein induces DNA damage in human peripheral blood Blymphocytes via mitochondrial ROS production. Redox Biol. 2018;15:97-108.

16. Lazzi S, Bellan C, De Falco G, Cinti C, Farrari F, Nyongo A, et al. Expression of RB2/p130 tumor-suppressor gene in AIDS-related non-Hodgkin's lymphomas: implications for disease pathogenesis. Hum Pathol. 2002;33(70):723-31.

17. Sall F, El Amine R, Markozashvili D, Tsfasman T, Oksenhendler E, Lipinski M, et al. HIV-1 tat protein induces aberrant activation of AICDA in human Blymphocytes from peripheral blood. J Cell Physiol. 2019. https://doi.org/10 1002/jcp.28219.

18. Asmaciogullari S, Pizzato M. The activity of Nef on HIV-1 infectivity. Front Microbiol. 2014;5(232):1-12

19. Ferdin J, Goricar K, Dolzan V, Plementas A, Martin JN, Peterlin BM, et al. Viral protein Nef is detected in plasma of half of HIV-infected adults with undetectable plasma HIV RNA. PLoS One. 2018;13(1):e0191613.

20. Gupta MK, Kaminski R, Mullen B, Gordon J, Burdo TH, Chueng JY, et al. HIV-1 Nef-induced cardiotoxicity through dysregulation of autophagy. Sci Rep. 2017;7(1):8572

21. Chagnon-Choquet J, Gauvin J, Roger J, Fontaine J, Poudier J, Roger M. HIV Nef promotes expression of B-lymphocyte stimulator by blood dendritic cells during HIV infection in humans. J Infect Dis. 2015;211(8):1229-40.

22. Xu W, Santini PA, Sullivan JS, He B, Shan M, Ball SC, et al. HIV-1 evades virusspecific lgG2 and lgA responses by targeting systemic and intestinal B cells via long-range intercellular conduits. Nat Immunol. 2009;10(9):1008-17.

23. Hessol NA, Martinez-Maza O, Levine AM, et al. Lung cancer incidence and survival among HIV-infected and uninfected women and men. AIDS. 2015; 29:1183-93.

24. Santerre M, Chatila W, Wang Y, Mukerjee R, Sawaya BE. HIV-1 Nef promotes cell proliferation and microRNA dysregulation in lung cells. Cell Cycle. 2019; 18(2):130-42.

25. Xue M, Yao S, Hu M, Hu M, Li W, Hao T, et al. HIV-1 Nef and KSHV oncogene $\mathrm{K} 1$ synergistically promote angiogenesis by inducing cellular miR-718 to regulate the PTEN/AKT/mTOR signaling pathway. Nucleic Acids Res. 2014:42(15):9862-79.

26. Freshney Rl. Culture of animal cells: A manual of basic technique and specialized applications, 6th ed, Wiley, New Jersey, USA, 2011:279-297.

27. Joseph AM, Ladha JS, Mojamdar M, Mitra D. Human immunodeficiency virus-1 Nef protein interacts with tat andenhances HIV-1 gene expression. FEBS Lett. 2003;1(3):37-42.

28. Narute PS, Smithgall TE. Nef alleles from all major HIV-1 clades activate Srcfamily kinases and enhance HIV-1 replication in an inhibitor-sensitive manner. PLoS One. 2012;7(2):e32561.

29. Challagundla KB, Sun X-X, Zhang X, DeVine T, Zhang Q, Sears RC, et al. Ribosomal protein $L 11$ recruits miR-24/miRISC to repress c-Myc expression in response to ribosomal stress. Mol Cell Biol. 2011;31(19):4007-21.

30. Varin A, Manna SK, Quivy V, Decrion A-Z, Van Lint C, Herbein G, et al. Exogenous Nef protein activates NF-kB, AP-1, and c-Jun N-terminal kinase and stimulates HIV transcription in promonocytic cells. J Biol Chem. 2003; 278(4):2219-27.

31. Raymond AD, Campbell-Sims TC, Khan M, Lang M, Huang MB, Bond VC, Powell MD. HIV type $1 \mathrm{Nef}$ is released from infected cells in CD45 microvesicles and is present in the plasma of HIV-infected individuals. AIDS Res Hum Retrovir. 2011;27(2):167-78.

32. Lamers SL, Fogel GB, Huysentruyt LC, McGrath MS. HIV-1 Nef protein visits B-cells via macrophage nanotubes: a mechanism for AIDS-related lymphoma pathogenesis? Curr HIV Res. 2010;8(8):638-40.
33. Rawat $P$, Mitra D. Cellular heat shock factor 1 positively regulates human immunodeficiency virus-1 gene expression and replication by two distinct pathways. Nucleic Acids Res. 2011;39(14):5879-92.

34. Muthumani K, Choo AY, Shedlock DJ, Laddy DJ, Sundaram SG, Hirao L, et al. Human immunideficiency virus type 1 Nef induces programmed death 1 expression through a p38 mitogen-activated protein kinase-dependent mechanism. J Virol. 2008;82(23):11536-44.

35. Zahn A, Eranki AK, Patenaude A-M, Methot SP, Fifield H, Cortizas EM, et al. Activation induced deaminase C-terminal domain links DNA breaks to end protection and repair during class switch recombination. Proc Natl Acad Sci U S A. 2014;111(11):988-97.

36. Valdiglesias V, Giunta S, Fenech M, Neri M, Bonassi S. $\gamma H 2 A X$ as a marker of DNA double strand breaks and genomic instability in human population studies. Mutat Res. 2013;753(1):24-40.

37. Epeldegui M, Breen EC, Hung YP, Boscardin WJ, Detels R, Martínez-Maza O. Elevated expression of activation induced cytidine deaminase in peripheral blood mononuclear cells precedes AIDS-NHL diagnosis. AIDS. 2007;21(17):2265-70.

38. Park i-W, Fan Y, Luo X, Ryou M-G, Liu J, Green L, He JJ. HIV-Nef is transferred from expressing $T$ cells to hepatocytic cells through conduits and enhances HCV replication. PLoS One. 2014;(96):e99545.

39. Shinmura K, Igarashi H, Goto M, Tao H, Yamada H, Matsuura S, et al. Aberrant expression and mutation-inducing activity of AID in human lung cancer. Ann Surg Oncol. 2011;18(7):2084-92

40. Takai A, Marusawa H, Minaki Y, Watanabe T, Nakase H, Kinoshita K, et al. Targeting activation-induced cytidine deaminase prevents colon cancer development despite persistent colonic inflammation. Oncogene. 2012:31:1733-42.

41. Nonaka T, Toda $Y$, Hiai H, Uemura M, Nakamura M, Yamamoto $N$, et al. Involvement of activation-induced cytidine deaminase in skin cancer development. J Clin Invest. 2016;126(4):1367-82.

42. Germini D, Tsfasman T, Klibi M, El-Amine R, Pichugin A, Larovaia OV, et al. HIV tat induces a prolonged MYC relocation next to IGH in circulating Bcells. Leukemia. 2017;31(11):2515-22.

43. Chen J, Liu T, Gao J, Gao L, Zhou L, Cai M, Shi Y, Xiong W, Jiang J, Tong T, Wang H. Variation in Carbohydrates between Cancer and Normal Cell Membranes Revealed by Super-Resolution Fluorescence Imaging. Adv Sci (Weinh). 2016;3(12):1600270.

\section{Publisher's Note}

Springer Nature remains neutral with regard to jurisdictional claims in published maps and institutional affiliations.
Ready to submit your research? Choose BMC and benefit from:

- fast, convenient online submission

- thorough peer review by experienced researchers in your field

- rapid publication on acceptance

- support for research data, including large and complex data types

- gold Open Access which fosters wider collaboration and increased citations

- maximum visibility for your research: over $100 \mathrm{M}$ website views per year

At $\mathrm{BMC}$, research is always in progress.

Learn more biomedcentral.com/submission 